\title{
Síndrome de Horner congénito con heterocromía de iris
}

\section{Congenital Horner's syndrome with iris heterochromia}

\author{
Mercedes Molero-Senosiain*, Liseth Salazar-Quiñones, Irene Camacho-Bosca, Álvaro Corrales-Benítez \\ y Enrique Santos-Bueso \\ Hospital Clínico San Carlos, Madrid, España
}

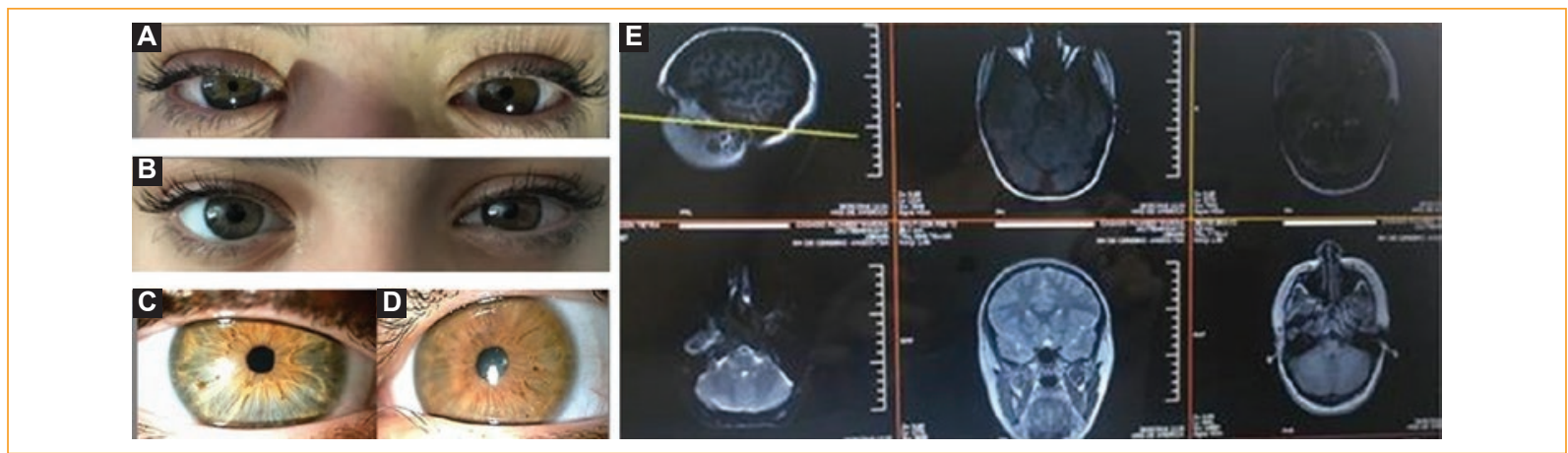

Figura 1. A: anisocoria con la pupila izquierda más miótica y el párpado superior izquierdo ptósico, al ser explorada en condiciones escotópicas. B: tras la administración de apraclonidina hidrocloruro (lopimax ${ }^{\circledR}$ ), la anisocoria persiste, pero se ha invertido al igual que la ptosis, y ahora la pupila izquierda es la más midríatica. C,D: heterocromía iridiana en lámpara de hendidura. E: múltiples cortes de imagen de resonancia nuclear magnética.

Mujer de 20 años que fue remitida a neuroftalmología por anisocoria y heterocromía de iris. Se le diagnosticó síndrome de Horner izquierdo por malformación vascular a nivel del plexo carotídeo mediante angiorresonancia magnética nuclear (angio-RMN).

\section{Conflicto de intereses}

Los autores declaran que no existen conflicto de intereses.

\section{Responsabilidades éticas}

Protección de personas y animales. Los autores declaran que para esta investigación no se han realizado experimentos en seres humanos ni en animales.

Confidencialidad de los datos. Los autores declaran que han seguido los protocolos de su centro de trabajo sobre la publicación de datos de pacientes.

Derecho a la privacidad y consentimiento informado. Los autores han obtenido el consentimiento informado de los pacientes y/o sujetos referidos en el artículo. Este documento obra en poder del autor de correspondencia.

\section{Bibliografía}

1. Pardal Souto MJ, Alas Barbeito AB, Taboada Perianes M. Congenital Horner's syndrome. An Pediatr (Barc). 2015;82(5):e213-4.

2. Renard D, Jeanjean L, Labauge $P$. Heterochromia Iridis in congenital Horner's syndrome. Eur Neurol. 2010;63(4):253.

\section{Correspondencia:}

